\section{Theories of general personality and mental}

\section{disorder*}

\author{
CONOR DUGGAN, JOHN MILTON, VINCE EGAN, LUCY MCCARTHY, \\ BEN PALMER and ALAN LEE
}

\begin{abstract}
Background A major shortcoming of current research into personality is its failure to explore the relationship between theories of general personality and mental disorder.
\end{abstract}

Aims To provide preliminary data to address this deficit.

Method In the first of two studies, we examined the relationship between the Neuroticism, Extraversion and Other Five-Factor Inventory (NEO-FFI) and DSM personality disorders in a consecutive series of mentally disordered offenders. In the second, we sought to separate the personality dimension neuroticism from symptoms of depressive disorder in a sample of subjects with current depression.

\section{Results Factors from the NEO-FFI} were associated with different personality disorders in a predictable manner (first study). It was possible to identify a component of neuroticism (i.e. 'worry') that could be separated from depressive symptoms (second study).

\section{Conclusions Theories of general} personality theory can enlighten and refine descriptions of abnormal mental states by informing both their aetiology and their prognosis.

\section{Declaration of interest None.}

* Paper presented at the second conference of the British and Irish Group for the Study of Personality Disorders (BIGSPD), University of Leicester, UK, 3I January to 3 February 200I.

\section{Personality disorder}

The title of this article subsumes two different issues that we wish to explore. First, what is the relationship between theories of personality and personality disorder? Second, what is the relationship between theories of personality and mental illness?

\section{Relationship between theories of personality and personality disorder}

\section{Personality theories}

The main personality theories are those of Cloninger (1987), Eysenck (1987), Costa \& McCrae (1990) and Watson et al (1994); and the circumflex models of Wiggins (1979) and Kiesler (1982), the latter being a circular arrangement of interpersonal dispositions around the orthogonal dimensions of dominance $(v$. submission) and nurturance ( $v$. hostility). Broadly, the first four models encompass three main dimensions: neuroticism, extraversion and one (or more, depending on the specific theory) other dimension that is less well-defined. Neuroticism, or negative emotionality, represents a tendency to see the world as threatening; extraversion, or positive emotionality, is a tendency to engage and confront the world. The Neuroticism, Extraversion and Other Five-Factor Inventory (NEO-FFI) is currently the most generally accepted dimensional model of personality and includes the following five factors: neuroticism, extraversion, openness, agreeableness and conscientiousness (Costa \& McCrae, 1990).

There are a number of difficulties in the reliability and validity of personality disorder classification (Zimmerman, 1994) together with problems of overlap between its different categories (Benjamin, 1993). The latter has identified as another major weakness the absence of any theory underpinning the personality disorder prototypes. General personality trait theory, as described above, could provide such a theoretical model so that the personality disorders within DSM are seen as being related to extreme variants of a continuous distribution of general personality traits.

\section{Personality traits and personality disorders}

There are surprisingly few studies that have examined the relationship between general personality traits and personality disorders. An exception is a study by Widiger et al (1994), who investigated the relationship between the NEO-FFI and the DSM-III-R and DSM-IV. They found that most personality disorders had a strong association with agreeableness and that avoidant personality disorder was a combination of high neuroticism and low extraversion. Another investigation, by Mulder et al (1999), examined the relationship of Cloninger's Temperament and Character Inventory (TCI) scale (of general personality) with DSM-III-R personality disorder (as assessed by the Structured Clinical Interview for DSM-IV Personality Disorders (SCID-II). This found, as predicted, that high novelty-seeking was associated with Cluster B personality disorders, high harm-avoidance with Cluster C, and low reward-dependence and high harmavoidance with Cluster A.

\section{Relationship between personality theory and mental illness}

Here DSM-III is a major advance, in that it separates Axis II conditions (i.e. personality disorder and learning difficulty) from Axis I conditions (i.e. the major mental illness syndromes). This separation of personality (trait-related) difficulties from mental syndromes (state-related) has not only led to important personality disorder research initiatives (Skodol, 1997) but has also encouraged an examination of the relationship between conditions on these two separate axes.

\section{Relationship of personality vulnerability to mental illness}

In an important conceptual article, Akiskal et al (1983) described four ways in which personality vulnerability might be related to a mental illness (in their discussion, it was depressive disorder). They suggested that a vulnerable personality might cause the disorder (i.e. be pathogenic); affect the 
course and outcome of the disorder (i.e. be pathoplastic); itself be a consequence of repeated episodes of illness; and be on a continuum where the personality vulnerability is seen as an attenuated form of the Axis I condition.

\section{Neuroticism and depression}

If we focus on major depression, neuroticism is the trait that has received the greatest attention in both clinical (Lloyd \& Lishman, 1975; Scott, 1988) and theoretical publications (Martin, 1985). Neuroticism, for instance, has been shown to exert a pathogenic effect on the development of depression (Angst \& Clayton, 1986) and to be raised in those with remitted depression (Hirschfeld et al, 1989; Maier et al, 1992). A number of studies have also shown that raised neuroticism during an episode of depression is associated with a poor long-term outcome (Andrews et al, 1990; Reich \& Vasile, 1993) so that it also exerts a pathoplastic effect. The claim that high neuroticism might be a result of repeated episodes of depression (i.e. the consequential or 'scar' hypothesis) has received only equivocal support.

Despite these positive associations, the relationship between raised neuroticism and depression has also been criticised. First, it has been observed that the state of being depressed influences the reporting of the trait of neuroticism, thereby contradicting Eysenck's claim that the trait ought to be independent of an individual's state (Kendell \& Discipio, 1968). Second, it has been argued that the association is a measurement artefact because neuroticism and depressive symptoms share a number of items in common. Katz \& McGuffin (1987), in a family study, found that whereas individuals with remitted depression had higher neuroticism scores than their first-degree relatives who had never been depressed, this elevation in neuroticism disappeared after they controlled for subclinical depressive symptoms. They concluded that the raised neuroticism in those with remitted depression was due to unmeasured subclinical depression.

Duggan et al (1995), in another family study, confirmed that individuals with remitted depression had higher neuroticism than their first-degree healthy relatives. A factor analysis of the individual items on both the Eysenck Personality Inventory Neuroticism (EPI-N) and Beck Depression
Inventory (BDI; Beck et al, 1961), measured contemporaneously, showed that it was possible to separate four factors, the first two of which were predominantly depressive symptoms and the second two neuroticism items. Entering these items into a forward logistic regression model with a past history of depression as the dependent variable showed that questions in the EPI-N associated with 'worrying' (the key Eysenckian descriptor of neuroticism) were those that were most predictive in identifying individuals who had had previous depression (Duggan, 1995).

The above study suffered from three major deficits: the sample size was only 150 , it was highly selective and the individuals were not depressed at the time of measuring their neuroticism. Our two studies sought to replicate these earlier findings while addressing the study's limitations by using a larger sample derived from general practice attendees who were depressed when their BDI and neuroticism were measured. The investigations aim to illustrate the clinical utility of combining personality traits with psychopathological conditions.

\section{METHOD}

\section{First study}

We used a similar set of measures to the Widiger et al (1994) study, to report on the relationship between measures of general personality and personality disorder in a group of male offenders, all of whom had at least one personality disorder. We examined a consecutive series of 34 men with an offending history and a personality disorder who were referred to a regional secure unit for treatment. These subjects were assessed using the self-rated NEOFFI and the interview version of the International Personality Disorder Examination (IPDE) (Loranger et al, 1994), administered by two experienced raters (C.D., J.M.) who were blind to the subject's NEO-FFI. The IPDE (interview version), although not a dimensional instrument, can produce a dimensional score by summarising all of the positive scores $(0$, not present; 1 , partly present; 2 , definitely present) for each of the traits examined in the different personality disorders. We correlated the IPDE scores obtained in this manner with those reported from the self-report NEO-FFI.

\section{Second study}

We examined the relationship between neuroticism and depressive symptoms in a sample of subjects with current depression drawn from a partially randomised patient preference trial designed to examine the efficacy of generic counselling $v$. antidepressants in a group of general practice attendees diagnosed with major depression. The characteristics of the sample have already been described (Bedi et al, 2000; Chilvers et al, 2001). All the subjects met the research diagnostic criteria for major depression and were asked to complete a BDI and EPI as part of the entry protocol. These data were analysed using Factor Analysis SPSS version 9 for Windows.

\section{RESULTS}

\section{First study}

The mean age for the subjects examined was 28.3 years (s.d. $=8.2$ years), and their mean full-scale IQ assessed using the Wechsler Adult Intelligence Scale (Psychological Corporation, 1998) was 88.2 $(\mathrm{s.d} .=15.0)$. All had a history of offences and in most this was extensive. The percentages of patients meeting criteria for a definite diagnosis for the various personality disorders were: paranoid, $26.5 \%$; schizoid, $11.8 \%$; schizotypal, $14.7 \%$; antisocial, $76.5 \%$; borderline, $61.8 \%$; histrionic, $17.6 \%$; narcissistic, $8.8 \%$; avoidant, $32.4 \%$; dependent, $11.8 \%$; obsessive-compulsive, $8.8 \%$; passive-aggressive, $44.1 \%$; sadistic, $20.6 \%$; and self-defeating, $8.8 \%$. Comorbidity between the different personality disorders was common. The mean (s.d.) NEO-FFI scores for the sample on the NEO-FFI were: neuroticism, 33.1 (6.9); extraversion, 20.4 (6.7); openness, 24.9 (5.9); agreeableness, 22.2 (7.3); and conscientiousness 25.5 (8.8).

Table 1 is a correlation matrix between the NEO-FFI and the dimensional scores from the IPDE interview. Given the small number of subjects and multiple testing with a likelihood of spurious associations, it is probably more valuable to look at the broad trends rather than individual associations. Here we found that the results do have a face validity in that the one negative dimension (neuroticism) was the only measure that showed positive correlations with all the personality disorders except schizoid personality disorder. Conversely, the other four positive dimensions of 
Table I Correlation matrix of NEO-FFI and IPDE interview (DSM classification-dimensional scores)

\begin{tabular}{lccccc}
\hline \multirow{2}{*}{$\begin{array}{l}\text { Personality } \\
\text { disorder }\end{array}$} & Neuroticism & Extraversion & Openness & Agreeableness & Conscientiousness \\
\cline { 2 - 6 } & $0.51^{* *}$ & $-0.41^{* *}$ & $-0.43^{* *}$ & $-0.41^{* *}$ & $-0.30^{*}$ \\
\hline Paranoid & -0.03 & $-0.35^{*}$ & -0.09 & 0.22 & -0.19 \\
Schizoid & 0.14 & $-0.33^{*}$ & -0.23 & 0.14 & -0.08 \\
Schizotypal & 0.23 & -0.02 & -0.13 & -0.12 & $-0.30^{*}$ \\
Antisocial & $0.49^{* *}$ & -0.09 & $-0.29^{*}$ & -0.13 & $-0.30^{*}$ \\
Borderline & 0.24 & -0.11 & $-0.38^{*}$ & -0.14 & 0.08 \\
Histrionic & 0.27 & -0.13 & -0.23 & -0.25 & -0.3 \\
Narcissistic & 0.16 & $-0.36^{*}$ & -0.22 & -0.07 & -0.05 \\
Avoidant & $0.38^{*}$ & -0.21 & $-0.45^{* *}$ & -0.25 & -0.13 \\
Dependent & 0.20 & $-0.35^{*}$ & -0.24 & 0.00 & -0.16 \\
Compulsive & $0.30^{*}$ & -0.16 & $-0.35^{*}$ & -0.26 & -0.24 \\
Passive-aggressive & 0.20 & -0.18 & -0.18 & -0.07 & $-0.45^{* *}$ \\
Sadistic & $0.48^{* *}$ & -0.10 & 0.15 & -0.05 & 0.00 \\
Self-defeating & 0.15 &
\end{tabular}

NEO-FFI, Neuroticism, Extraversion and Other - Five-Factor Inventory; IPDE, International Personality Disorder Examination.

*Correlation is significant at the 0.05 level (I-tailed), **Correlation is significant at the 0.01 level (I-tailed). personality in the NEO-FFI almost all showed negative correlations with the range of personality disorders investigated. The implications of these findings will be examined further in the Discussion.

\section{Second study}

There were 323 subjects in the trial and 263 $(81 \%)$ completed the two questionnaires. The mean (s.d.) of their neuroticism and BDI scores were 15.5 (5.0) and 26.1 (8.2), respectively. As there were no differences in baseline or outcome data between the four different groups in the study (i.e. the two randomised and the two preference arms), we collapsed the data and analysed them as a single data-set.

The factor analysis showed that there were ten meaningful factors that accounted for $56 \%$ of the variance in those who were entered into the trial and completed the questionnaires (Table 2). The first factor consisted of BDI depressive (i.e. 'state') items. Factors 2-6 comprised neuroticism ('trait') items. Factor 2, accounting for $11 \%$ of the variance, comprised items 43 , $23,40,14$, and 28 of the neuroticism scale that related to 'worry and guilt'. This replicated the finding in the earlier study identifying these traits as being a key component of neuroticism in those who were currently depressed.
Table 2 Factor analysis of the EPI-N and BDI

\begin{tabular}{lccc}
\hline Factor & Eigenvalue & \% of variance & Cumulative \% \\
\hline I: All Beck items & 8.824 & 19.610 & 19.610 \\
2: EPI-N items 43, 23, 40, 14, 28 ('worry and guilt') & 4.946 & 10.991 & 30.601 \\
3: EPI-N items 26, 47 ('nervous/highly strung') & 1.985 & 4.412 & 35.013 \\
4: EPI-N items 2, 9, 7 ('moods') & 1.616 & 3.592 & 38.605 \\
5: EPI-N items 50, 16, 52 ('sensitive') & 1.593 & 3.540 & 42.144 \\
6: EPI-N items 45, 55 ('health') & 1.403 & 3.119 & 45.263 \\
7: Beck items 18, 19 ('appetite/weight') & 1.304 & 2.897 & 48.160 \\
8: EPI-N items 33, 35 ('palpitations/trembling') & 1.252 & 2.782 & 50.942 \\
9: EPI-N items 57, 3I+Beck item I6 ('sleeplessness') & 1.221 & 2.714 & 53.656 \\
I0: EPI-N items 4, 38 ('irritable') & 1.146 & 2.546 & 56.201 \\
\hline
\end{tabular}

EPI-N, Eysenck Personality Inventory - Neuroticism; BDI, Beck Depression Inventory.
These results help illuminate a common clinical dilemma when one attempts to separate trait vulnerability from state in an individual who is depressed. The data suggest that it is possible to identify a subset of items that conform to Eysenck's original core construct of neuroticism (Eysenck \& Eysenck, 1975) that is separate from the state of being depressed. Furthermore, we conjecture that it is these items, when elevated in a subject with current depression, that make such an individual vulnerable to a poor longterm course and hence that might be a marker to identify subjects that ought to be the target for longer-term maintenance treatment.

\section{DISCUSSION}

DSM-IV, with its biaxial subdivision of mental illness and personality disorder, is currently under review (Liversley, 2000). It has been suggested that this separation should be discontinued so that both mental illness and personality disorder are included in the same axis in future revisions of DSM (Liversley, 1998). Given our current state of knowledge, we believe that this integration is premature and that our gaze ought to remain bifocal. We argue that retaining this biaxial approach will focus attention on the relationship between conditions on these two axes that might otherwise be lost. A specific interest in personality, moreover, enriches one's understanding of mental illness. Millon $\&$ Frances (1987) put this position eloquently when they wrote justifying the biaxial approach adopted in DSM-III that 'personality ... . was assigned a contextual role that made it fundamental to the understanding and interpretation of other psychopathologies'.

Costa \& McCrae (1994), who were responsible for the development of the NEO-FFI, introduced a model of personality development that includes what they termed 'basic tendencies' and 'characteristic adaptations'. 'Basic tendencies' refer to largely inherited dispositions or traits (similar to the elements in the NEO-FFI) that interact with the environment to produce 'characteristic adaptations'. The latter conjunction involves elements that are relatively fixed (i.e. are characteristic) and others that are fluid (i.e. influenced by the environment). 
'Characteristic adaptations' are therefore the material that mental health professionals deal with and that deserve our attention. We suggest that the findings from these two studies have two implications. The first concerns aetiology. This model suggests that a personality disorder or a mental illness might result from the interaction of a basic tendency (such as high neuroticism) with a less than optimal environment. Although some basic tendencies (such as a high neuroticism score) could render an individual more prone to a mental disorder, others (e.g. raised extraversion or openness) might exert an opposite effect and be protective. The first of our two studies offers some evidence in support of this view.

The second implication concerns prognosis. Given that the provision of services for those with mental disorder is predicated on the belief that limited resources ought to be targeted at those who most require them, the heterogeneity of mental disorders creates major problems for service planners. It is clear that further categorisation is necessary to identify those who might benefit from specific interventions. We believe that the combination of general personality theory with clinical theories of psychopathology, as shown in our second study, is one way in which more homogeneous entities might be identified. Features of neuroticism might identify, for instance, those individuals who are likely to have a poor long-term course and hence are worthy of special consideration. In addition, we believe that this conjunction would enrich both theoretical formulations and clinical practice.

\section{REFERENCES}

Akiskal, H. S., Hirschfield, P. M. A. \& Yerevanian, B. I. (1983) The relationship of personality to affective disorders: a critical review. Archives of General Psychiatry, 40, $80 \mid-810$.

Andrews, G., Neilson, M., Hunt, C., et al (1990) Diagnosis, personality and long-term outcome of depression. British Journal of Psychiatry, 157, 13-18.

Angst, J. \& Clayton, P. (1986) Premorbid personality of depressive, bipolar and schizophrenic patients with special reference to suicidal issues. Comprehensive Psychiatry, 27, 51I-532.

Beck, A.T., Ward, C. H., Mendelson, M., et al (1961) An inventory for measuring depression. Archives of General Psychiatry, 4, 56I-57I.

Bedi, N., Lee, A., Harrison, G., et al (2000) Assessing effectiveness of treatment in depression in primary care: Partially randomised preference trial. British Journal of Psychiatry, 177, 312-318.

\section{CLINICAL IMPLICATIONS}

Measures of general personality and personality disorder are related to one another in a predictable manner.

- Certain dimensions (e.g. neuroticism) have mainly positive associations with personality disorders, whereas others (e.g. extraversion) have the reverse, indicating that such dimensions may exert either a predisposing or a protective effect in the development of personality disorder.

- It has been possible to identify a core construct of neuroticism that is independent of the state of being depressed.

\section{LIMITATIONS}

- Other measures of personality and psychopathology could have been investigated.

- The numbers in the first study were small, so the results can be regarded only as suggestive.

- Further refinement and replication of the Eysenck Personality Inventory Neuroticism and the Beck Depression Inventory data would be necessary to make it clinically relevant.

C. DUGGAN, FRCPsych, J. MILTON, MRCPsych, East Midlands Centre for Forensic Mental Health, Leicester; V. EGAN, ClinPsychD, Department of Psychology, Glasgow Caledonian University; L. McCARTHY, PhD, East Midlands Centre for Forensic Mental Health, Leicester; B. PALMER, MSc, Trent Institute for Health Services Research, University of Nottingham Medical School, Queen's Medical Centre, Nottingham; A. LEE, FRCPsych, Department of Psychiatry, University Hospital, Queen's Medical Centre, Nottingham, UK

Correspondence: C. Duggan, East Midlands Centre for Forensic Mental Health, University of Leicester, Arnold Lodge, Cordelia Close, Leicester LE5 OLE, UK

Benjamin, L. S. (1993) Interpersonal Diagnosis and Treatment of Personality Disorders. New York, USA: Guilford Press.

Chilvers, C., Dewey, M., Fielding, K., et al (200I) Antidepressant drugs and generic counselling for treatment of major depression in primary care: randomised trial with patient preference arms. BMJ, 322, 772-775.

Cloninger, C. R. (1987) A systematic method for clinica description and classification of personality variants. Archives of General Psychiatry, 44, 573-588.

Costa, P. T. \& McCrae, R. (1990) Personality disorders and the five-factor model of personality. Journal of Personality Disorders, 4, 362-37I.

— \& _ (1994) Set like plaster? Evidence for the stability of adult personality. In Can Personality Change? (eds T. F. Heatherton \& J. L.Weinberger), pp. $21-40$ Washington, DC: American Psychological Association.

Duggan, C. (1995) Maudsley Depressives - An Aetiologic and Long-Term Outcome Perspective. MD thesis. Cork: University College, National University of Ireland.

_ , Sham, P., Lee, A., et al (1995) Neuroticism: a vulnerability marker for depression evidence from a family study. Journal of Affective Disorders, 35, 139-143.
Eysenck, H. (1987) The definition of personality disorders and the criteria appropriate for their description. Journal of Personality Disorders, 1, 211-219.

— \& Eysenck, S. B. G. (1975) Manual of the Eysenck Personality Questionnaire. London: Hodder \& Stoughton.

Hirschfeld, R. M. A., Klerman, G. L., Lavori, P., et al (1989) Premorbid personality assessments of first onset of major depression. Archives of General Psychiatry, 46, 345-350.

Katz, R. \& McGuffin, P. (1987) Neuroticism in familial depression. Psychological Medicine, 17, 155-161.

Kendell, R. E. \& DiScipio, W. J. (1968) Eysenck personality inventory scores of patients with depressive illnesses. British Journal of Psychiatry, II4, 767-770.

Kiesler, D. J. (1982) The 1982 Interpersonal Circle: a taxonomy for complementarity in human transactions. Psychological Review, 90, 185-214.

Liversley, W. J. (1998) Suggestions for a framework for an empirically based classification of personality disorder. Canadian Journal of Psychiatry, 30, 137-147.

- (2000) Introduction to critical issues in the classification of personality disorder. Journal of Personality Disorders, 14, I-2.

Lloyd, G. G. \& Lishman, W. A. (1975) Effect of depression on the speed of recall of pleasant and 
unpleasant memories. Psychological Medicine, 5, $173-180$

Loranger, A.W., Sartorius, N., Andreoli, A., et al (1994) The International Personality Disorder

Examination: the WHO/ADAMHA international pilot study of personality disorders. Archives of General Psychiatry, 51, 215-224.

Maier, W., Lichtermann, D., Minges, J., et al (1992) Personality traits in subjects at risk for unipolar major depression: a family study perspective. Journal of Affective Disorders, 24, 153-164.

Martin, M. (1985) Neuroticism as predisposition toward depression: a cognitive mechanism. Personality and Individual Differences, 6 (3), 353-365.

Millon, T. \& Frances, A. J. (1987) (editorial). Journal of Personality Disorders, I, i-iii.
Mulder, R. T., Joyce, P. R., Sullivan, P. F., et al (1999) The relationship among three models of personality psychopathology: DSM-III-R personality disorder, TCI scores and DSQ defences. Psychological Medicine, 29, 943-951.

Psychological Corporation (1998) Wechsler Adult Intelligence Scale (3rd edn). London: Psychological Corporation.

Reich, J. H. \& Vasile, R. G. (1993) Effect of personality disorders on the treatment outcome of Axis I conditions: an update. Journal of Nervous and Mental Disease, I8I, 475-484.

Scott, J. (1988) Chronic depression. British Journal of Psychiatry, 153, 287-297.

Skodol, A. E. (1997) Classification, assessment and differential diagnosis of personality disorder. Journal of Practical Psychiatry and Behavioural Health, 3, 26I-274.
Watson, D., Clark, L. A. \& Harkness, A. R. (1994) Structures of personality and their relevance to psychopathology. Journal of Abnormal Psychology, 103. |8-3|.

Widiger, T. A., Trull, T. J., Clarkin, J. F., et al (1994) A description of the DSM-III-R and DSM-IV personality disorders with the five-factor model of personality. In Personality Disorders and the Five Factor Model of Personality, pp. 4I-56. Washington, DC: American Psychological Association.

Wiggins, J. S. (1979) A psychological taxonomy of trait-descriptive terms: the interpersonal domain. Journal of Personality and Social Psychology, 37 395-412.

Zimmerman, M. (1994) Diagnosing personality disorders. A review of issues and research methods. Archives of General Psychiatry, 5 I (3), 225-245. 